\title{
WGPPM-Abstract for Poster Presentations
} 291 SERUM CONCENTRATIONS OF FIBRO ECTIN(FN), LAMININ JUVENILE PATIENTS WITH TYPE I DIABETES. K.Ullrich,M.Kleine, B.Voss ${ }^{\star}$, B.Högemann Univ.-Kinderklinik and Institut für Artherioskieroseforsch $1 g^{\star}$, Univ. Münster, FRG

Diabetes mellitus is associated with t ckening of basement membranes and changes of connective tis ue. FN and LM are the main noncollagenous basement membri le proteins. Both are discussed to be involved in fibril ogenesis. In tissuest of diabeticsenhanced cross-linking of collagen was found and in the serum elevated concentrations of different glycoproteins. - Thus we tested the serum concentrations of $F N, L M$ and $P$-III-P in 35 patients (age $12.0 \pm 4.3 \mathrm{y}$; $\mathrm{HbA}_{1}$ values $\left.9.1 \pm 2.0 \%\right)$ by lasernephelometry and radioimmunoassays using monospecific antisera as described earlier: (J.Clin.Chem.Clin.Biochem.18,893,1980;Anal.Biochem.113,372, 1981; Eur.J.Clin. Invest.9,451,1979). The patients showed no significant changes of serum $F N(18.4 \pm 5.7 \mathrm{mg} / \mathrm{dl}), \mathrm{LM}$ $(1.7 \pm 0.3 \mathrm{E} / \mathrm{ml})$ and $P-I I I-P$ concentrations $\left(26.7^{\prime} \pm 11.5 \mathrm{ng} /\right.$ $\mathrm{ml})$ as compared to controls $(19.4 \pm 8.5 \mathrm{mg} / \mathrm{dl} ; 1.4 \pm 0.1$ $\mathrm{E} / \mathrm{ml} ; 30.2 \pm 13.0 \mathrm{ng} / \mathrm{dl} ; n=20)$. No significant correlation was found between the concentrations of $H b A, F N, L M$ and $P$-III-P such as between FN and P-III-P. As sóme patients showed retinopathy and limited joint mobility these results indicate, that the serum concentrations of $F N$, $L M$ and P-III-P seem to be no markers for detection of early diabetic changes in basement membrane and connective tissue metabolism. \section{HIGH PLASMA FIBRONECTIN IN CHILDREN WITH POOR}

M. Borkenstein, W.Muntean (Introduced by O.Linderkamp) Dpt.Pediatrics, Univ. Kinderklinik Graz, Austria

Plasma fibronectin (PFN) was studied in 63 children and adolescents with type I diabetes and in $\mathbf{2 5}$ healthy controis. All subjects included in the study were without signs of microangiopathic disease: no retinal lesions were demonstrable, plasma creatinine levels were lower than $1.0 \mathrm{mg} / \mathrm{dl}$, and no proteinuria was demonstrable. The diabetic subjects were grouped according to their $\mathrm{HbA}_{1}$ values, the urinary sugar excretion, and the duration of clinical diabetes. PFN of the diabetic subjects was significantly higher than those of normal controls. The group with high $\mathrm{HbA}_{1}$ values had significantly higher PFN than the group with low $\mathrm{HbA}$, values. The group with high urinary sugar excretion had higher PFN values than the group with low urinary sugar excretion. PFN did not differ in the group with short or long duration of clinical diabetes.

Our results show that in diabetic children and adolsecents without diabetic vascular disease but poor control of diabetes increased PFN can be demonstrated. An elevation of PFN might have some significance in the pathogenesis or propagation of diabetic vascular disease. \section{RECORDINGS OF REACTIVE HYPEREMIA BY TRANS-} U Ewald, G Rooth, $T$ Tuvemo. Dept Pediatr, Uppsala, Sweden.

Transcutaneous $\mathrm{PO}_{2}(\mathrm{tcPO})$ at $37^{\circ} \mathrm{C}$ reflects tissue $\mathrm{PO}_{2}$ at the border between living and dead epidermis ( $50 \mathrm{um}$ depth). In contrast to its conventional use at $45^{\circ} \mathrm{C} \mathrm{tcPO}_{2}$ at $37^{\circ} \mathrm{C}$ is hardly affected by changes in Conventional use at $45^{\circ} \mathrm{C} \mathrm{tcPO}_{2}$ at $37^{\circ} \mathrm{C}$ is hardly affected by changes in
arterial $\mathrm{PO}_{2}$ but very dependent on changes in skin blood flow. Laser Doppler arterial $\mathrm{PO}_{2}$ but very dependent on changes in skin blood flow. Laser Doppler
velocimetry (LDV) measures the speed of moving erythrocytes in the skin to a depth of $1000 \mathrm{um}$. The aim of this work was to compare these methods for noninvasive recording of reactive hyperemia in the skin.

$A$ combined $\mathrm{tCPO}_{2}$ electrode incorporating the LDV measuring probe (Periflux ${ }^{R}$ ) was constructed in Huch's laboratory, Zürich, allowing recordings from the same skin site simultaneously under identical experimental conditions. The combined sensor was placed on the volar aspect of the forearm. Exercise induced and postocclusive reactive hyperemia were recorded in healthy induced and postocch

Both signals detected small rhytmical variations in steady state and recorded biphasically the changes in skin blood flow during and after reactive hyperemia. The time course differed between the $\mathrm{tcPO}_{2}$ and the LDV signal, the former being delayed about $30 \mathrm{~s}$ for the postocclusive response. A significant correlation between the postocclusive maximal peaks measured by the two methods was found $(r=0.7 ; p<0.01 ; n=20)$, but no correlation between corresponding recordings during steady state or exercise.

Since the methods measure at different depth they convey information on blood flow changes in different vascular beds. LDV measurements include shunt blood flow in the subpapillary plexa, while tcPOO selectively measures capillary, nutritive blood flow. The time delay between the signals is partly explained by this difference in types of flow with different time constants, and partly by the time lag for a changing oxygen gradient to reach the electrode. 294 PRONOUNCED POS'TOCCLUSTVE REACTIVE HYPERAEMIA IN CHILDREN

U. Ewald*, G. Ah1sten*, T. Tuvemo, Dept. Paediatrics, University Hospital, s-75185 Uppsala, Sweden.

The initiation and development of vascular disease might start a1ready in childhood. Functional vascular disturbances should be possible to find in many progressive disorders as e.g. diabetes mellitus before structural lesions develop. Such findings could suggest clues for understanding and be suitable for studies of pathogenetic mechanisms. Postocclusive reactive hyperaemia is a coomonly used physiological test of vascular function. We have earlier shown that this response is readily detected by a transcutaneous oxygen electrode used at $37^{\circ} \mathrm{C}$ (SJCLI 1981; 41: 641, Lancet 1981; $i:$ 1287). The method has the advantage of being non-invasive and measures changes occuring in defined skin vessel regions.

Results: A statistically significant difference in the postischaemic Results: A statistically significant difference in the postischaem
peak tcP ${ }_{2}$ was found between healthy children and adults. Thus 34 healthy children aged $5-18$ showed a value of $4.0 \pm 1.0 \mathrm{kPa}$ compared with $2.6+1.0 \mathrm{kPa}$ for 67 healthy adults aged $22-60$ years $(\mathrm{p}<0.001)$. A corrolation coefficient between the log. age and the postischaemic peak of $-0.63(p<0.01)$ was found. In the group of children no significant sex difference in the postocclusive peak $t c \mathrm{PO}_{2}$ was observed (boys $3.8+1.2$ and girls $4.1+0.8 \mathrm{kPa}$ respectively; $0.05<p<0.1$ ) whereas among the 67 healthy adults, females $(n=30)$ showed significantl higher postischaemic peak $\mathrm{tcPO}_{2}$ values than males $(3.2 \pm 0.9$ and $2.1+0.8$ $\mathrm{kPa}$ respectively; $<0.001)$. Conclusions: A significant decrease in vascular response to tissue ischaemia occurs already during childhood. Studies on risk factors for development of vascular disease should therefore start alreagdy in children.
295 CHLORPROMAZINE TREATMENT OF PERSISTENT PULMONARY HYPERTENSION IN THE NEWBORI

M. Katona, P. Hencz, E. Kertēsz, P. Tekulics, J. Beviz (Introduced by 0 . Linderkamp) Paediatric Department, Medical University, Szeged, Hungary

The treatment of persistent pulmonary hypertension in the newborn (PPHN) has not been settled yet. Alpha-adrenergic blocking drugs widely used in the treatment of PPHN may exhibit serious side effects. In various hypoxemic states chlorpromazine (CPZ) has been recently reported to improve hypoxia, presumably due to the alphaadrenergic blocking effect (Larsson et al. 1982). The aim of the present study was to assess the possible therapeutic value of CPZ in PPHN. Criteria for establishing the diagnos is of PPHN were: hypoxemia refractory to CPAP or PEEP ventilation, enhancement of the difference between pre- and postductal $\mathrm{PaO}_{2}$, hyperoxia-hyperventilation test and M-mode echocardiography in differentiating PPHN from congenital heart defects. 13 neonates with PPHN who had $\mathrm{PaO}_{2}<50$ torr at 100\% oxygen were studied. CPZ was administered into a peripheral vein or umbilical artery catheter in a dose of $0.5-1.0 \mathrm{mg} / \mathrm{kg} / \mathrm{h}$ As $\mathrm{Pa}_{2}$ began to rise the dosage was gradually lowered to $0.1 \mathrm{mg} / \mathrm{kg} / \mathrm{h}$ lo of the 13 patients survived. In 11 neonates the $\mathrm{PaO}_{2}$ increased substantially. Two patients, who developed symptoms of patent ductus arteriosus, were given Indomethacin, and the ductus closed. In conclusion, the use of CPZ in the treatment of PPHN seems to be a promising new approach without unexpected side effects.

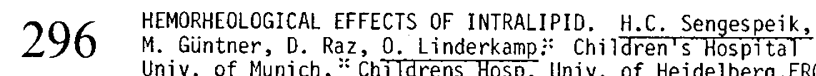
Univ. Of Munich, "Chitrens Hosp. Univ. of Heidelberg, FRG Gas exchange impairment occuring with intralipid (IL) infusion has been related to disturbed pulmonary microcirculation due to lipid glo-
bules, altered red cells $(\mathrm{RBC})$ membrane composition and enhanced $\mathrm{RBC}$ bules, altered red cells(RBC) membrane composition and enhanced RBC
and platelet aggregation. Hemorheological effects of IL were studied using a cone-plate viscometer (whole blood and plasma viscosity), filtration method (filtrability of RBC), rheoscope (RBC deformability), and light transmission (RBC aggregation). IL $(0.15 \mathrm{~g} / \mathrm{kg} / \mathrm{h})$ was infused in 10 preterm and 10 full term infants. Blood samples were studied prior to and at the end of insufion $(4 \mathrm{~h})$. None of the hemorheological methods showed abnormal results. In vitro RBC from lo preterm, 10 term infants and 10 adults were suspended in plasma and buffer and were studied after 3 and $6 \mathrm{~h}$ of incubation with IL at concentrations of $0,1,2,4$ and $8 \mathrm{mg} / \mathrm{ml}$ of RBC. Whole blood and plasma viscosity and $R B C$ deformability were not al tered by IL. However, RBC aggregation decreased markedly with increasing IL concentration. RBC filtration was significantly impaired in the presence of IL both in plasma and in buffer. RBC were also incubated with IL, then washed and resuspended in IL free plasma and buffer before filtration. These cell showed normal filtration rate. We conclude that hemorheological alterations occuring at high IL concentrations are not the result alterations occuring at high IL concentrations are not the result
of altered RBC deformability and aggregation but rather due to plasma hyperlipemia causing obstruction of filter pores and possibly of capillaries. 